\title{
LETTERS
}

\section{Daily analgesia for nonheadache pain may not lead to daily rebound headaches}

I read with interest the article on medication-overuse headache by Micieli and Robblee. ${ }^{1}$ I have a hard time attributing so many patients' chronic headaches to medication overuse.

I definitely have a group of patients who take analgesics daily (or nearly so), have persistent headaches and have received the diagnosis of medicationoveruse headache.

I have a similar group of patients who have infrequent headaches, but they do have back pain for which they take analgesics daily. Yet these patients who take analgesics daily for another reason have not had their intermittent headaches turn into daily headaches from analgesic rebound.

So why blame the first group's daily headaches on analgesic rebound or overuse? The second group did not get rebound headaches from daily analgesics.

Other factors may be causing daily headaches for these patients. Analgesic rebound, or overuse, seems to be the preferred diagnosis of many clinicians, when it is not necessarily etiologic.

\section{Steve Blitzer MD}

Chronic pain specialist, Mackenzie Health, Richmond Hill, Ont.

Cite as: CMAJ 2018 July 30;190:E914. doi: $10.1503 / \mathrm{cmaj} .69420$

\section{Reference}

1. Micieli A, Robblee J. Medication-overuse headache. CMAJ 2018;190:E296.

Competing interests: None declared. 